\title{
Distribution and Performance of the Nonnative Seagrass Zostera japonica across a Tidal Height Gradient on Shaw Island, Washington ${ }^{1}$
}

Kevin H. Britton-Simmons, ${ }^{2,5,6}$ Sandy Wyllie-Echeverria ${ }^{2,3}$ Elizabeth K. Day, ${ }^{2}$ Katherine P. Booth, ${ }^{2}$ Kelsey Cartwright, ${ }^{2}$ Susana Flores, ${ }^{2}$ Cheyenne C. Garcia, ${ }^{2}$ Tessa L. Higgins, ${ }^{2}$ Cynthia Montanez, ${ }^{2}$ Arielle Rames, ${ }^{2}$ Kasey M. Welch, ${ }^{2}$ and Victoria Wyllie-Echeverria ${ }^{2,4}$

\begin{abstract}
In the Northeast Pacific the nonnative seagrass Zostera japonica frequently exists at the same sites as the native seagrass Zostera marina. Although at some sites their vertical distributions overlap, at most sites in the Pacific Northwest there is a distinctive unvegetated zone between them. The objective of this study was to better understand why a gap between the lower limit of $Z$. japonica and the upper limit of Z. marina exists. To address this issue we carried out transplant experiments, conducted in situ monitoring of existing Z. japonica patches, and collected sediment samples at South Beach on Shaw Island, Washington, during the spring and summer of 2006. Transplant and in situ monitoring data indicate that survival and performance of $Z$. japonica are reduced lower in the intertidal zone. In addition, Z. japonica patches tended to be smaller and more spaced out at lower tidal heights. Although we found no Z. japonica seeds within or outside extant Z. japonica patches, high transplant mortality indicates that Z. japonica dispersal limitation is an unlikely cause of the unvegetated gap zone. Our field observations further suggest that herbivory, bioturbation, and epiphytes are unlikely causes of the gap pattern at our study site. Instead, we hypothesize that light limitation prevents $Z$. japonica from occurring lower in the intertidal. A review of published vertical distribution data for both Zostera species indicates that the lower limit of $Z$. japonica is relatively invariant among sites. In contrast, the upper limit of $Z$. marina is highly variable, ranging by more than $4 \mathrm{~m}$ within some subregions in Washington State. Consequently we hypothesize that intersite variability in the vertical distribution of $Z$. marina is the primary driver of spatial variability in the presence of the unvegetated gap.
\end{abstract}

THE SPREAD of nonnative species is a global problem with substantial economic and ecological consequences (Mack et al. 2000, Pimentel et al. 2005). Marine and estuarine habitats in the Puget Sound region of the United States have been invaded by numer-

\footnotetext{
${ }^{1}$ The research reported here was largely carried out as part of an undergraduate course on bioinvasions at Shannon Point Marine Center and was supported financially by SPMC, Western Washington University, and NSF grant OCE-0228618. Manuscript accepted 20 April 2009.
}

Pacific Science (2010), vol. 64, no. 2:187-198

doi: $10.2984 / 64.2 .187$

(C) 2010 by University of Hawai'i Press

All rights reserved ous nonnative species (Cohen et al. 2000), some of which have caused ecological and economic damage (e.g., Spartina anglica [see Hacker et al. 2001]). Zostera japonica Ascherson \& Graebner is a common species in the northern Puget Sound region, including the

\footnotetext{
2 Shannon Point Marine Center, Western Washington University, 1900 Shannon Point Road, Anacortes, Washington 98221.

${ }^{3}$ Friday Harbor Laboratories, University of Washington, 620 University Road, Friday Harbor, Washington 98250 .

${ }^{4}$ School of Environmental Studies, University of Victoria, Victoria, British Columbia V8W 2Y2, Canada.

${ }^{5}$ Current address: University of Washington, Friday Harbor Laboratories, 620 University Road, Friday Harbor, Washington 98250 (fax: 206-543-1273; phone: 360378-2165).

${ }^{6}$ Corresponding author (e-mail: aquaman@u .washington.edu)
} 
San Juan Islands. Zostera japonica was introduced sometime before 1957 (Harrison and Bigley 1982) and is now widespread in coastal areas of British Columbia, Washington, and Oregon (Nomme and Harrison 1991a,b). It is thought that Z. japonica arrived accidentally as a hitchhiker on the Pacific oyster (Crassostrea gigas), which was imported to this region for aquaculture beginning in the early twentieth century (Harrison and Bigley 1982).

Much of the concern surrounding introduced species stems from the potential for negative interactions with native species (Grosholz et al. 2000, Byers 2002, Levin et al. 2002). Indeed, throughout much of its distribution in this region $Z$. japonica co-occurs at the same sites as the native seagrass Zostera marina L. However, because of their respective vertical distributions there is little overlap in the habitats used by these two species. Whereas Z. marina extends from the subtidal into the lower intertidal, Z. japonica occurs primarily in the high intertidal zone, with some populations extending into the lower intertidal, where the distributions of these two seagrasses sometimes overlap (Nomme and Harrison 1991b, Baldwin and Lovvorn 1994). When Z. japonica and Z. marina encounter one another there is the potential for competitive interactions to occur. Zostera marina has much longer and wider leaves and experiments in the laboratory and field suggest that it is the superior competitor (Nomme and Harrison 1991a,b). Consequently, it has been suggested that the lower limit for Z. japonica may be set by competitive interactions with $Z$. marina (Nomme and Harrison 1991a,b).

At many sites in the Northeast Pacific there is no overlap in the vertical distribution of Z. japonica and Z. marina (69\% of sites [Shafer 2007]). At those sites there is a distinct unvegetated zone in the mid- to low intertidal zone (hereafter referred to as a "gap zone") that separates the upper edge of $Z$. marina and the lower edge of $Z$. japonica. Considering that Z. japonica is generally capable of surviving in the low intertidal and shallow subtidal zones (Nomme and Harrison $1991 b$ ) and that it grows better when continuously submerged (Harrison 1982), it should be able to grow at the tidal heights where these unvegetated strata occur. In this study we focused on three research questions: (1) Can Z. japonica survive above and below its natural vertical range if transplanted into the extreme high intertidal and into the unvegetated gap zone? (2) Is there a difference in the performance of $Z$. japonica at the upper and lower edges of its natural vertical range? (3) What is the role of seeds in maintaining distribution patterns? To address these questions we carried out transplant experiments, conducted in situ monitoring of existing $Z$. japonica patches, and collected core samples at South Beach on Shaw Island, Washington, during the spring and summer of 2006.

\section{MATERIALS AND METHODS}

\section{Site Description}

Our study site was South Beach (also known as Indian Cove), located on the southeastern side of Shaw Island in the San Juan Islands, Washington State, USA $\left(48^{\circ} 33.845^{\prime} \mathrm{N}, 122^{\circ}\right.$ $\left.56.131^{\prime} \mathrm{W}\right)$. South Beach is a sandy intertidal site that is exposed to the southwest, the direction from which the dominant winds blow in that area. Zostera japonica populates a gently sloping beach in a relatively large intertidal zone and consists of approximately 100 patches that vary in size (see schematic representation in Figure 1). In contrast, the Zostera marina bed, the upper edge of which began in the lower intertidal, was relatively uniform, lacking the patchiness that was characteristic of Z. japonica. Sampling occurred on 17 April, 15 May, and 13 July 2006. Bioturbating organisms such as burrowing shrimp have not been observed at this site since at least 1996 (S.W.-E., pers. obs.).

\section{Vertical Distribution of Zostera spp.}

We measured the vertical distribution of $Z$. japonica and Z. marina along eight randomly placed vertical transects in the intertidal zone at South Beach (Figure 1). Along each transect we measured the tidal heights at the lower and upper limits of Z. japonica and the 


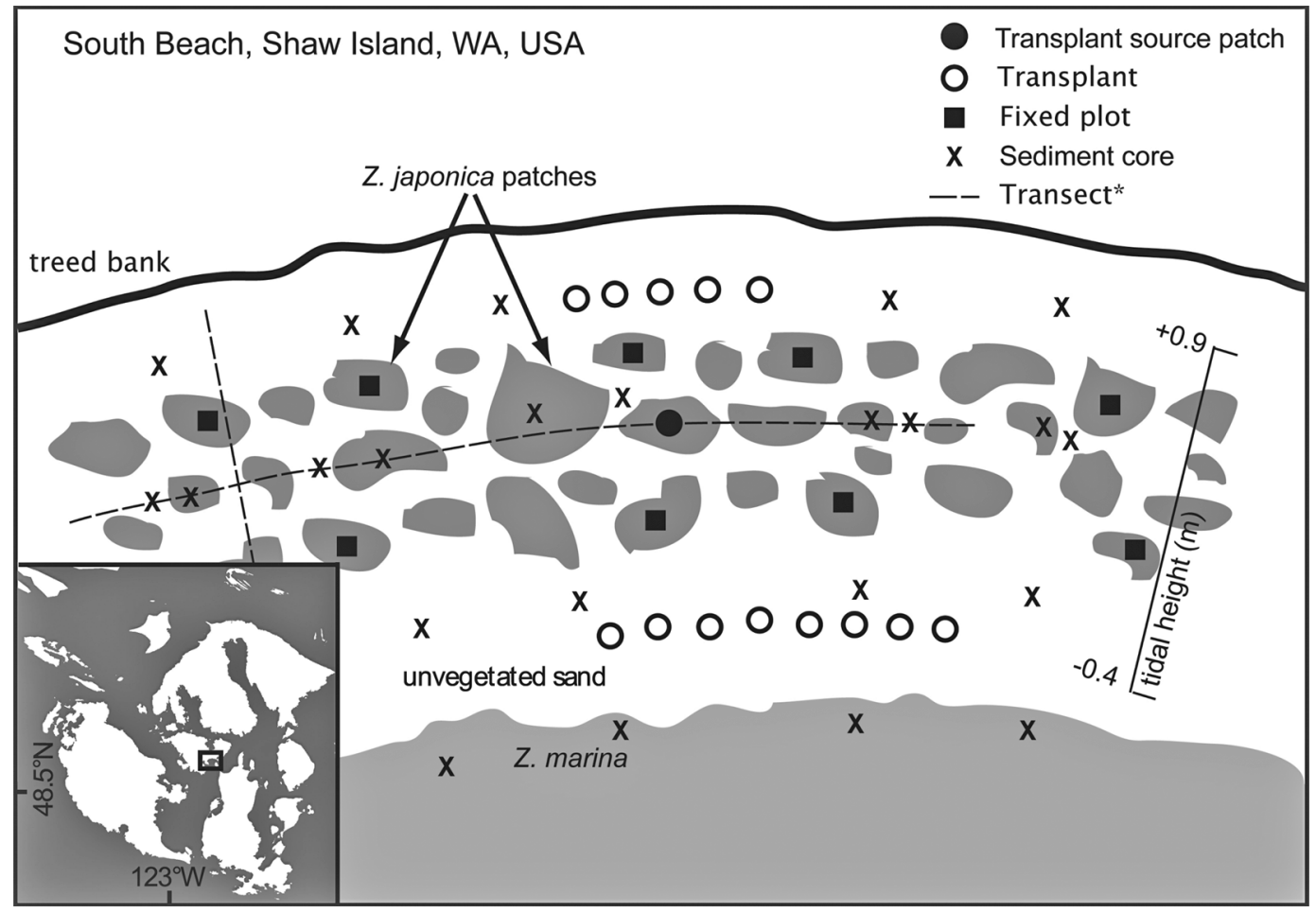

Figure 1. Schematic diagram of South Beach study site and sampling methodology. Inset shows San Juan Archipelago, Washington, USA. For clarity only one horizontal (three total) and one vertical (eight total) transects are shown. Three of the low transplants were used for biomass production sampling. Diagram is not to scale.

upper limit of Z. marina. All tidal height measurements were taken using standard transit survey equipment and tide tables. In addition, we measured the distance along the substrate between the bottom of the Z. japon$i c a$ bed and the top of the Z. marina bed (i.e., the size of the gap zone between the two species).

\section{Patch Width and Spacing}

We measured the spatial distribution of Z. japonica patches at three tidal heights: $5 \mathrm{~m}$ below the upper limit of the bed, the vertical center of the bed, and $5 \mathrm{~m}$ above the bottom edge of the bed. At each of these tidal heights we laid a $200 \mathrm{~m}$ transect across the beach and measured the width of all patches bisected by the transect as well as the distance between patches along the transect (Figure 1).

\section{Fixed Plots}

Fixed plots were established at two tidal heights near the upper and lower limits of $Z$. japonica, at approximately $+0.4 \mathrm{~m}$ mean lower low water (MLLW) and $0 \mathrm{~m} \mathrm{MLLW,} \mathrm{re-}$ spectively. At each of the two tidal heights five $Z$. japonica patches at approximately the same tidal height and separated by between 10 and $30 \mathrm{~m}$ were haphazardly selected. A fixed plot measuring $30 \mathrm{~cm}$ by $30 \mathrm{~cm}$ was established at the center of each patch (Figure 1).

Using a $30 \mathrm{~cm}$ by $30 \mathrm{~cm}$ quadrat subdivided into nine uniform sections, we estimated the percentage cover of leaves and counted the number of shoots in three randomly selected subsections within each quadrat. We then randomly selected three $Z$. japonica shoots from within the plot, counted 
the number of leaves per shoot, and measured the length and width (1 $\mathrm{mm}$ above the sheath) of the longest leaf of each shoot selected. Data from these samples were averaged for each plot to increase the precision of numbers used in statistical analyses. The presence or absence of an intact leaf tip was also noted.

Plots were established and data were initially collected on 17 April 2006. They were subsequently resampled on 15 May and 13 July 2006.

\section{Transplants}

Phillips (1976) discussed the value of transplanting as a technique to assess the tolerance of seagrass species to a range of environmental conditions. We transplanted Z. japonica to two tidal heights: +0.9 m MLLW and -0.2 $\mathrm{m}$ MLLW on 17 April 2006. The higherelevation transplant location was above the $Z$. japonica distribution and the lower elevation transplant was located in the unvegetated zone, between Z. japonica and Z. marina (Figure 1). Our transplant technique involved removing a $10 \mathrm{~cm}$ diameter intact rhizocore (whole plant shoots and associated sediment) with a polyvinyl chloride corer to create a transplant unit. Each transplant unit was planted into an excavated hole created using the same coring device. All transplant units were taken from a single Z. japonica patch located near the vertical center of the population.

Five cores were transplanted to the higher elevation and eight cores were transplanted to the lower elevation. The shoots from three of the low transplant units were excised $1 \mathrm{~cm}$ above the sediment immediately after transplanting. Shoots from these treatments were excised on each subsequent sample date using the same technique to quantify aboveground biomass production. Tissue was bagged separately and transported to the laboratory, where it was dried to a constant weight at $60^{\circ} \mathrm{C}$ and weighed to the nearest milligram. Shoots in the remaining five cores in the lower elevation zone and all of the transplant cores at the upper tidal height were kept intact for shoot density counts and to measure the longest leaf of five haphazardly selected shoots in each unit on each sample date. No transplant control treatment was used to evaluate the effect of transplanting.

\section{Seed Bank Evaluation}

On 17 April we collected sediment cores along five vertical transects. Each transect was laid so that it bisected a Z. japonica patch at approximately the midpoint of the vertical distribution of the $Z$. japonica population. The location of the first transect was haphazardly chosen. However, the subsequent four transect locations were determined by measuring a horizontal distance along the beach $23 \mathrm{~m}$ from the previous transect and selecting the patch that was closest to that point and approximately at the midpoint of $Z$. japonica's vertical distribution. The transect was then laid so that it bisected this patch. Sediment cores $(5 \mathrm{~cm}$ diameter, $10 \mathrm{~cm}$ depth) were then collected at four tidal heights along each transect: above the $Z$. japonica zone $(+0.9 \mathrm{~m} \mathrm{MLLW})$, within the $Z$. japonica zone $(+0.2 \mathrm{~m}$ MLLW), the unvegetated zone between the two Zostera species $(-0.1$ $\mathrm{m}$ MLLW), and just inside the $Z$. marina bed (-0.6 m MLLW) (Figure 1).

At the sampling station within the Z. japonica bed we collected two cores: one in the patch bisected by the transect and one in unvegetated sand at the same tidal height. At all other sampling stations we collected a single core per tidal height. Thus we collected five cores per transect along five transects for a total of 25 cores. Cores were transported to the laboratory, where they were sieved in a nest of five mesh sizes $(10 \mathrm{~mm}$, $1.4 \mathrm{~mm}, 1 \mathrm{~mm}, 0.8 \mathrm{~mm}, 0.2 \mathrm{~mm}$ ) to capture the range of $Z$. japonica seed sizes that occur $(2.38 \mathrm{~mm} \pm 0.119 \mathrm{~mm}$, mean \pm 1SD [Phillips and Menez 1988, Wyllie-Echeverria et al. 2006]). The contents of each sieve were examined using a dissecting microscope to look for the presence of seeds or seed coats.

\section{Statistics}

The patch width and distance between patch data were each analyzed independently using one-way analyses of variance (ANOVAs). 
Both data sets were natural log transformed before analysis to conform to the assumptions of ANOVA. Fixed plot data were analyzed using repeated measures ANOVA with tide height and time as main effects. The fixed plot percentage cover data were arcsine square-root transformed before repeated measures ANOVA analysis. We combined the broken leaf tip data for each tidal height across all sample dates and used a contingency test to ask whether the proportion of leaves that were broken differed between the two tidal heights (Sokal and Rohlf 1995). All data presented in figures are untransformed.

\section{RESULTS}

\section{Vertical Distribution of Zostera spp.}

The two species of Zostera present at South Beach have distinct, nonoverlapping vertical distributions (Figure 2). The average vertical range of $Z$. japonica was from $0.05 \mathrm{~m}$ to 0.34 $\mathrm{m}$ MLLW. The upper limit of the $Z$. marina averaged $-0.39 \mathrm{~m}$ MLLW. Thus, there was a vertical distance of $44 \mathrm{~cm}$ between the two species on the tide flat (Figure 2). Because the beach at this site was gently sloping this vertical gap translated into a large horizontal discontinuity. The average horizontal distance along the substratum between the two species was $22.2 \mathrm{~m} \pm 6.1 \mathrm{~m}$ (mean $\pm 1 \mathrm{SD})$.

\section{Patch Width and Spacing}

Both the patch width and patch spacing data were natural $\log$ transformed before analysis to conform to the assumptions of ANOVA. There was no difference in the width of $Z$. japonica patches among tidal heights (one-way ANOVA, $F=0.14$, df $=2, P=.86$ ) (Figure 3). Similarly, the distance between $Z$. japonica patches did not vary significantly across the vertical distribution occupied by this species (one-way ANOVA, $F=0.08, \mathrm{df}=2, P=$ .92) (Figure 3).

\section{Fixed Plots}

The percentage cover and shoot abundance data from fixed plots indicated that Z. japonica

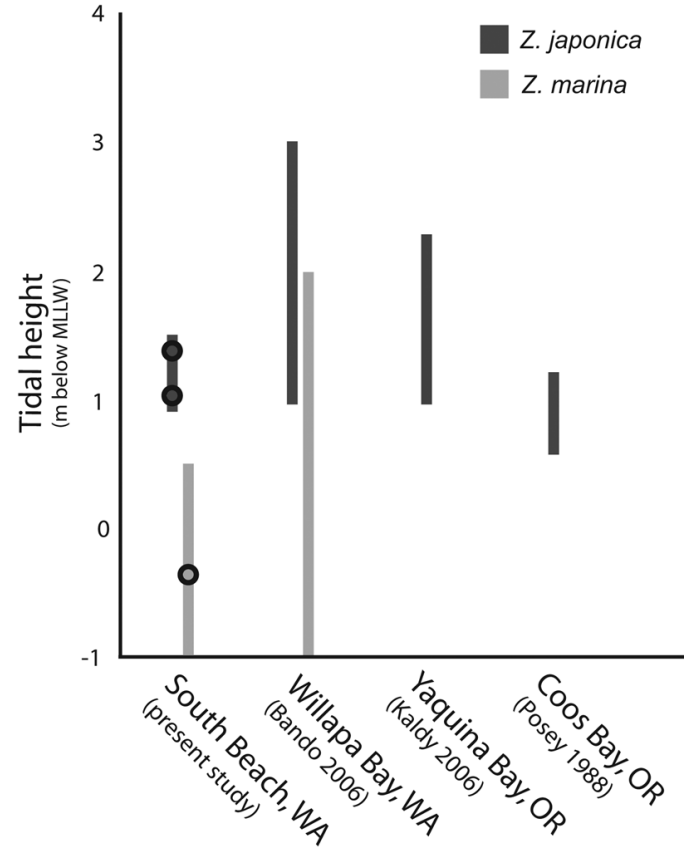

Figure 2. Vertical distribution of Z. japonica and Z. marina at South Beach ( $n=8$ transects) and three additional sites from the literature. Only one of the other studies reported tidal range data for Z. marina. Dark circles denote mean upper and lower tidal heights for the two species at our study site. At South Beach the average horizontal distance along the substratum between the top edge of the Z. marina bed and the bottom edge of the Z. japonica bed was $22.2 \mathrm{~m}$.

performed better in patches near the upper edge of its vertical distribution. Although the percentage cover of $Z$. japonica was very similar at the two tidal heights in April, it subsequently increased at the upper limit of the bed and decreased at the lower limit of the bed in May and July (Figure 4a). Tidal height explained a significant amount of variation $(P=.002)$ (Table 1$)$, indicating that percentage cover was (on average) significantly higher in patches at the upper limit of the population. The time effect was not significant $(P=.55)$ (Table 1$)$. However, a significant time by tidal height interaction occurred $(P=.028)$ (Table 1$)$ because the difference in percentage cover between the two treatments increased over time (Figure $4 a)$. 


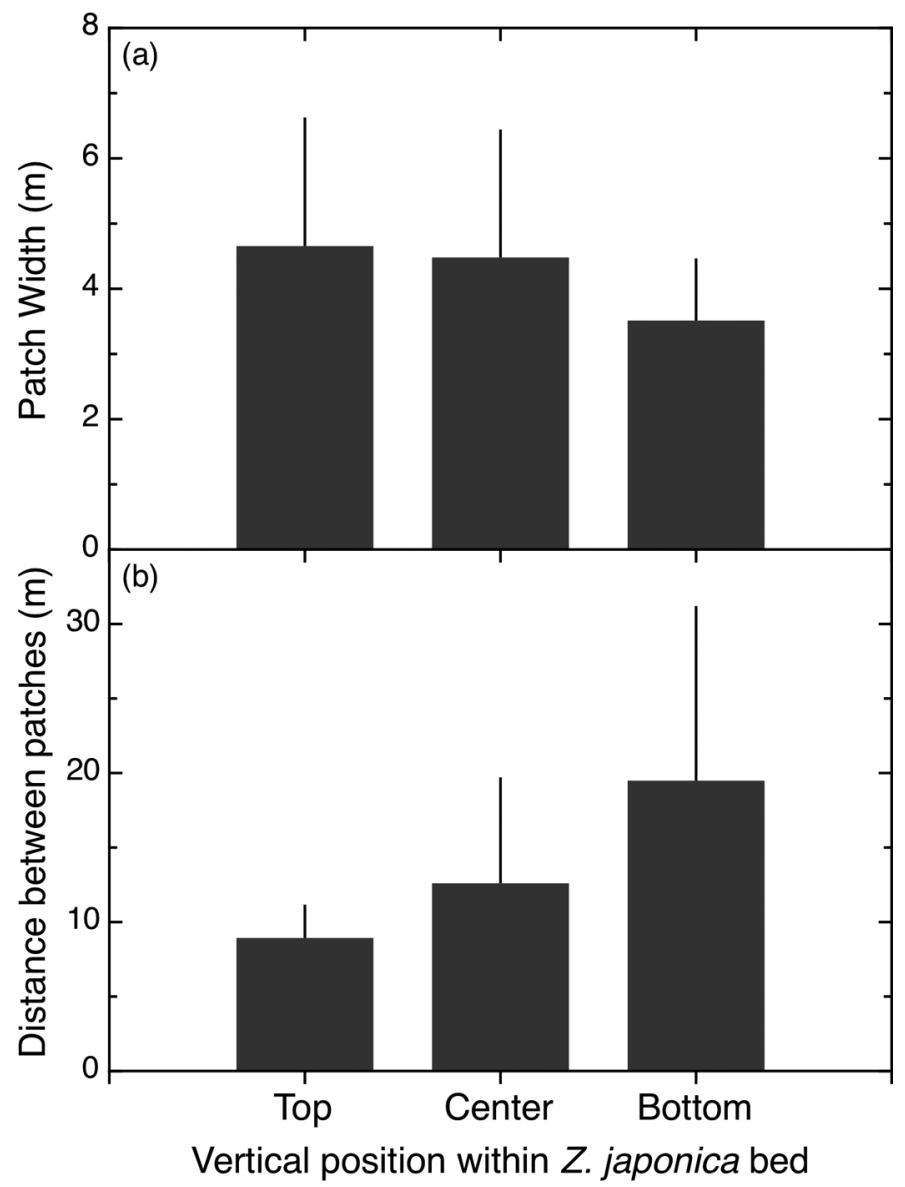

FIGURE 3. Width of $(a)$ and horizontal spacing between $(b)$ patches of Z. japonica at three tidal heights at South Beach $(n=3$ transects). The top and bottom measurements were taken $5 \mathrm{~m}$ inside the upper and lower edges of the bed, respectively. Data are means $\pm 1 \mathrm{SE}$.

The number of Z. japonica shoots in fixed plots was consistently higher in patches at the upper limit compared with those at the lower limit $(P=.009)$ (Table 1 , Figure $4 b)$. In addition, there was a significant effect of time in the ANOVA model as shoot density at both tidal heights initially increased between April and May and then decreased between May and July $(P=.003)$ (Table 1). Because the temporal dynamics in shoot density were synchronous in both upper and lower patches, the time by tidal height interaction was not significant $(P=.44)$ (Table 1 , Figure $4 b$ ).

The leaf length data indicate that Z. japon- ica leaves were longer at the upper limit compared with the lower limit (Figure $4 c$ ). The main effect of tidal height was not significant $(P=.06)$ (Table 1 ) because the leaves in high patches were initially slightly longer than those in low patches (Figure 4c). However, leaf length increased between April and July in the high patches but not in the low patches, as indicated by the significant time by tidal height interaction $(P=.007)$ (Table $1)$. During this 3 -month period leaves in the high patches increased in length by an average of $91 \%$, and those in low patches decreased in length by an average of $8 \%$ (Figure $4 c$ ). 
FIXED PLOTS
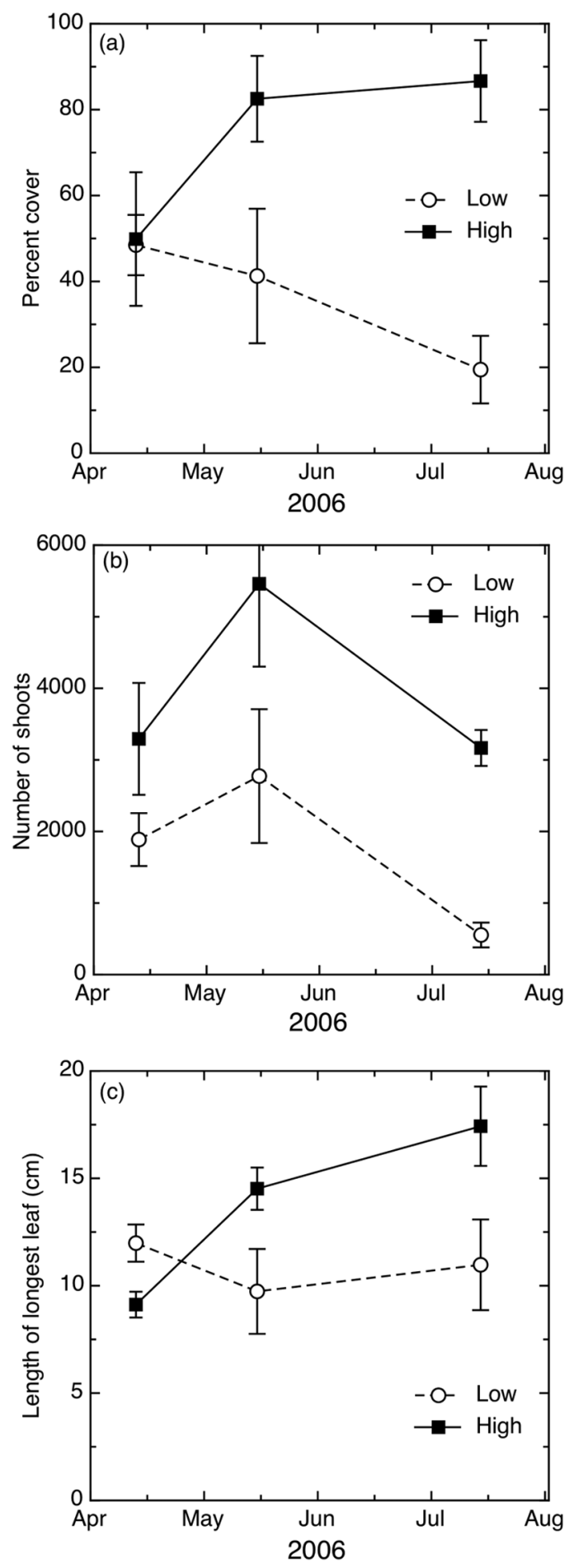

TABLE 1

Repeated Measures ANOVA Analyses of Fixed Plot Data

\begin{tabular}{|c|c|c|c|}
\hline Source of Variation & df & $F$ & $P$ \\
\hline \multicolumn{4}{|l|}{ Percentage cover } \\
\hline \multicolumn{4}{|l|}{ Between subjects } \\
\hline Tidal height & 1 & 18.89 & .002 \\
\hline Error & 8 & & \\
\hline \multicolumn{4}{|l|}{ Within subjects } \\
\hline Time & 2 & 0.63 & .55 \\
\hline Time $\times$ Tidal height & 2 & 4.50 & .028 \\
\hline Error & 16 & & \\
\hline \multicolumn{4}{|l|}{ Number of shoots } \\
\hline \multicolumn{4}{|l|}{ Between subjects } \\
\hline Tidal height & 1 & 11.64 & .009 \\
\hline Error & 8 & & \\
\hline \multicolumn{4}{|l|}{ Within subjects } \\
\hline Time & 2 & 8.79 & .003 \\
\hline Time $\times$ Tidal height & 2 & 0.85 & .44 \\
\hline Error & 16 & & \\
\hline \multicolumn{4}{|l|}{ Number of leaves } \\
\hline \multicolumn{4}{|l|}{ Between subjects } \\
\hline Tidal height & 1 & 0.04 & .84 \\
\hline Error & 8 & & \\
\hline \multicolumn{4}{|l|}{ Within subjects } \\
\hline Time & 2 & 0.53 & .60 \\
\hline Time $\times$ Tidal height & 2 & 2.28 & .13 \\
\hline Error & 16 & & \\
\hline \multicolumn{4}{|l|}{ Leaf width } \\
\hline \multicolumn{4}{|l|}{ Between subjects } \\
\hline Tidal height & 1 & 0.09 & .77 \\
\hline Error & 8 & & \\
\hline \multicolumn{4}{|l|}{ Within subjects } \\
\hline Time & 2 & 6.29 & .01 \\
\hline Time $\times$ Tidal height & 2 & 2.47 & .12 \\
\hline Error & 16 & & \\
\hline \multicolumn{4}{|l|}{ Length of longest leaf } \\
\hline \multicolumn{4}{|l|}{ Between subjects } \\
\hline Tidal height & 1 & 4.63 & .06 \\
\hline Error & 8 & & \\
\hline \multicolumn{4}{|l|}{ Within subjects } \\
\hline Time & 2 & 3.68 & .049 \\
\hline Time $\times$ Tidal height & 2 & 6.77 & .007 \\
\hline Error & 16 & & \\
\hline
\end{tabular}

There was no difference in the number of leaves per $Z$. japonica shoot between upper and lower patches $(P=.84)$ (Table 1$)$. Although there was significant variation over

Figure 4. Percentage cover (a), shoot density $(b)$, and leaf length $(c)$ in $Z$. japonica patches from fixed plots in upper and lower portions of the population at South Beach ( $n=5$ per tidal height). Shoot number is per $\mathrm{m}^{2}$ area. Data are means \pm 1 SE. 
time in leaf width $(P=.01)$ there was no indication that leaf width differed between the two tidal heights $(P=.77)$ (Table 1). The percentage of leaves with broken tips was $34 \%$ in high plots (15 of 44 leaves) and $42 \%$ in low plots (19 of 45 leaves) and was not significantly different $(G=0.62, P \gg .05)$.

\section{Transplants}

The high-elevation transplants were completely gone (i.e., no tissue, including rhizome remained) when we returned to the site in May (Figure 5). The lower-elevation transplants survived throughout our sampling period (Figure 5) but were missing when we visited the site in April 2007.

The biomass production in the clipped $Z$. japonica cores in the low-elevation zone was $76 \pm 39 \mathrm{mg}$ (mean \pm 1 SD) between April and May. Production from May to July was $283 \pm 206 \mathrm{mg}$ (mean \pm 1 SD), which on a per-month basis (i.e., divided by 2) yields an estimate of $141 \pm 103 \mathrm{mg}$ (mean $\pm 1 \mathrm{SD}$ ) during that period. Thus, the monthly productivity of the lower-elevation transplants doubled during the later months compared with the April-May interval.

\section{Sediment Cores}

No seeds from either species of Zostera were found in the 25 sediment cores.

\section{DISCUSSION}

The distinctive gap zone between the lower edge of $Z$. japonica and the upper edge of $Z$. marina at South Beach (Figure 2) is a pattern that occurs at the majority of sites in this region (Shafer 2007). At South Beach Z. japonica was present (on average) from $+0.05 \mathrm{~m}$ to $+0.34 \mathrm{~m}$, with a vertical distance of $0.44 \mathrm{~m}$ between Z. japonica and Z. marina. Although this distance is relatively small, on this gently sloping beach that translates into an average distance along the substratum of $22.2 \mathrm{~m}$. This gap zone is sufficiently large that the two seagrass species do not come into direct contact at this site. Although exploitation competition for water column nutrients could
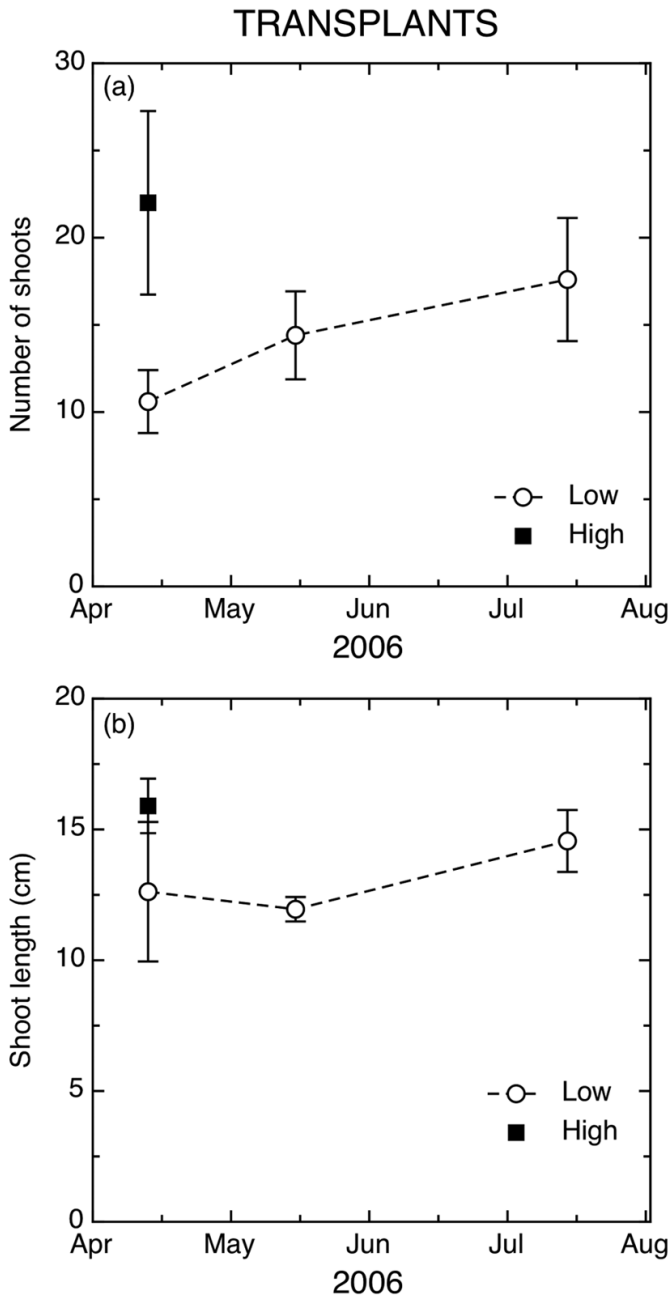

Figure 5. Performance of Z. japonica transplants, all of which were taken from a single patch in the center of the vertical distribution of $Z$. japonica ( $n=5$ transplants per treatment). All high-elevation transplants were gone by the May sample date. Low-elevation transplants did not survive over the winter. Data are means $\pm 1 \mathrm{SE}$.

still occur (Larned 2003), seagrass in this region is generally not nutrient limited (Phillips 1984), especially at relatively high-energy sites like South Beach. Therefore, we think it is unlikely that competition between the two seagrasses occurs at this site.

One goal of our study was to evaluate whether Z. japonica can survive above and be- 
low its natural vertical distribution at South Beach. When transplanted above its existing upper limit Z. japonica disappeared completely (including rhizomes) within 1 month (Figure $5)$. In the absence of transplant controls we cannot exclude the possibility that transplant stress contributed to the mortality of these transplants. Nevertheless, one possible explanation is that the transplants were eroded from the sandy substrate by wave action. This mechanism fits with our observation that the high intertidal substratum at South Beach was very dynamic and changed considerably between our visits. However, Z. japonica is relatively vulnerable to desiccation (Baldwin and Lovvorn 1994, Shafer et al. 2007), and a second potential explanation is that desiccation weakened the high transplants, facilitating their removal by water motion. The alternative hypothesis that herbivory caused the mortality in this zone is inconsistent with absence of rhizome material and lack of herbivores at this site.

Transplants of $Z$. japonica into the gap zone between the two seagrass species survived, and even increased in shoot number, throughout the summer but then disappeared during the winter. Likewise, Nomme and Harrison (1991b) found that Z. japonica transplanted into the low intertidal increased in shoot density during the summer months in British Columbia. Whereas the lower limit of $Z$. japonica may be set by competition with $Z$. marina at some sites (Nomme and Harrison 1991b), it appears to be determined by something else at sites like South Beach where the two species do not overlap. One possibility is herbivory by birds during the winter months, when migrating and overwintering birds feed intensively on $Z$. japonica in this region (Baldwin and Lovvorn 1994). However, birds such as dabbling ducks and black brant (Branta bernicla) have not been observed at South Beach (S.W.-E., pers. obs.). An alternative hypothesis is that light limitation precludes long-term survival in the low intertidal (Huong et al. 2003).

Does seed limitation play an important role in structuring the distribution of $Z$. japonica? We found no seeds in our coring study and we saw no evidence of $Z$. japonica flowering at this site. Because seed distribution within a Zostera population can be nonuniform (Boese and Robbins 2008) we cannot exclude the possibility that seeds were present at South Beach but not detected by our coring study. However, Z. japonica seeds persist in the sediment year-round and can be viable for multiple years (Bigley 1979), so we should have detected seeds if they were present, even if they were the result of flowering we have observed at this site in previous years (S.W.-E., pers. obs.). Given the complete absence of seeds it seems likely that growth of the South Beach Z. japonica population occurs primarily via expansion of existing patches. Fragmentation may also be a mechanism by which new patches are initiated, but it is unknown whether Z. japonica can generate new patches in that way, and the importance of fragmentation for seagrasses in general is debated (Ewanchuk and Williams 1996, Hall et al. 2006). Although the lack of seeds might suggest a role for dispersal limitation, the failure of long-term survival of our transplants indicates that dispersal limitation is probably not regulating the vertical distribution of $Z$. japonica at this site.

Our fixed-plot surveys clearly showed that $Z$. japonica performed better at the upper edge of its vertical distribution, compared with the lower edge (Figure 4). In addition, $Z$. japonica patches tended to be smaller and more distant from one another in the low intertidal compared with the high intertidal (Figure 3). These results collectively suggest that the high intertidal is better habitat for $Z$. japonica than is the low intertidal. One possible explanation is bioturbation (e.g., Burrowing shrimp [Dumbauld and WyllieEcheverria 2003]), but bioturbating organisms have not been observed at this site. Other possible reasons include herbivory, epiphyte load, and light. Aside from an occasional amphipod, we observed no herbivores in the vicinity of $Z$. japonica at this site. Thus, we think it unlikely that increased levels of herbivory in the lower intertidal can explain our results. The lack of herbivores at this site contrasts with the large number of gastropods and crustacean herbivores that 
have been found in association with Z. japonica at some other sites in this region (Thom et al. 1995) and in its native range (Fong et al. 2000), suggesting that there is considerable intersite and interregion variation in herbivore pressure. Epiphytic algae can have important effects on Z. japonica in other regions of the world (Fong et al. 2000). However, the only epiphytic algae we observed on Z. japonica at our site were diatoms and they were never abundant, possibly due to the wave-exposed nature of this beach.

In our view the most obvious explanation for the pattern we observed is that higher light availability in the upper intertidal zone resulted in enhanced $Z$. japonica performance. Although laboratory experiments indicate that Z. japonica performs better when continuously submerged (Harrison 1982), in the field being continuously submerged comes at a cost of reduced access to light. To our knowledge minimum light requirements for $Z$. japonica have not been measured. However, such data are available for $Z$. noltii, a species in the same subgenus (Bigley and Barreca 1982, den Hartog and Kuo 2006) with a comparable vertical distribution. Whereas $Z$. noltii requires a minimum of $15 \mathrm{~mol}$ quanta $\mathrm{m}^{-2}$ day $^{-1}$ to trigger rhizome branching (Vermaat and Verhagen 1996), Z. marina growth is unconstrained by light at just $7 \mathrm{~mol}$ quanta $\mathrm{m}^{-2}$ day $^{-1}$ (Thom et al. 2008). Likewise, the half saturation constant $\left(\mathrm{K}_{\mathrm{m}}\right)$ of $Z$. noltii is more than four times higher than that of $Z$. marina (Vermaat and Verhagen 1996). These data indicate that $Z$. noltii has much higher light requirements than $Z$. marina. To the extent that $Z$. noltii and $Z$. japonica light requirements are comparable, this provides some support for our hypothesis that light limitation may be a factor mediating $Z$. japonica performance near the lower edge of its vertical distribution.

Zostera japonica's tidal height-dependent performance notwithstanding, it is currently unclear which Zostera species is responsible for variation among sites in the presence of the unvegetated gap zone separating the two species in the Pacific Northwest. Available data on the vertical distribution of $Z$. japonica suggest that the lower limit of this species is relatively invariant, even when gap and nongap sites are considered (Figure 2). Conversely, $Z$. marina distribution data suggest that its upper edge is highly variable in this region (Figure 2) (Bando 2006, Gaeckle et al. 2008). A large-scale (79 sites) monitoring program in the Greater Puget Sound confirms that the upper limit of Z. marina is extremely variable within Washington State, ranging more than $4 \mathrm{~m}$ in some subregions (Gaeckle et al. 2008). Thus, we propose that $Z$. marina is the species responsible for generating the unvegetated gap zone. Specifically, we hypothesize that the gap zone occurs at sites where the upper limit of Z. marina is constrained (e.g., South Beach [Figure 2]; see also Boese and Robbins 2008). Regardless of whether Z. marina plays a key role in generating the gap pattern, an important next step to understanding its genesis is to identify how sites at which the gap is present differ from those where it is absent. No studies have addressed this issue directly, but Shafer (2007) suggested that abiotic habitat parameters may control variability among sites in the presence of the gap.

Overall our results suggest that Z. japonica performance is dependent on tidal height, with reduced performance lower in the intertidal. This pattern is largely consistent with prior work (Bigley and Harrison 1986, Nomme and Harrison 1991b, Shafer 2007). However, previous Z. japonica studies have focused on sites where the vertical distribution of $Z$. japonica overlaps with that of $Z$. marina. Our study provides information about the distribution and abundance of Z. japonica at a second, and more common (Shafer 2007), type of site: those where the two Zostera species do not come into direct contact.

\section{ACKNOWLEDGMENTS}

We are grateful to the staff of Shannon Point Marine Center, especially Brandon Jensen, for logistical support. For assistance in the field we thank Sylvia Yang and Tessa Wyllie-Echeverria. Two anonymous reviewers provided helpful comments on the paper. S.W.-E. thanks the Russell Family Foundation for partial support. 


\section{Literature Cited}

Baldwin, J. R., and J. R. Lovvorn. 1994. Expansion of seagrass habitat by the exotic Zostera japonica, and its use by dabbling ducks and brant in Boundary Bay, British Columbia. Mar. Ecol. Prog. Ser. 103:119127.

Bando, K. J. 2006. The roles of competition and disturbance in a marine invasion. Biol. Invasions 8:755-763.

Bigley, R. E. 1979. The population biology of two intertidal seagrasses, Zostera japonica and Ruppia maritima at Robert's Bank, British Columbia. M.S. thesis, University of British Columbia, Vancouver.

Bigley, R. E., and J. L. Barreca. 1982. Evidence for synonymizing Zostera americana den Hartog with Zostera japonica Aschers. \& Graebn. Aquat. Bot. 14:349-356.

Bigley, R. E., and P. G. Harrison. 1986. Shoot demography and morphology of Zostera japonica and Ruppia maritima from British Columbia, Canada. Aquat. Bot. 24:69-82.

Boese, B. L., and B. D. Robbins. 2008. Effects of erosion and macroalgae on intertidal eelgrass (Zostera marina) in a northeastern Pacific estuary (USA). Bot. Mar. 51:247-257.

Byers, J. E. 2002. Impact of non-indigenous species on natives enhanced by anthropogenic alteration of selection regimes. Oikos 97:449-458.

Cohen, A., H. Berry, C. Mills, D. Milne, K. Britton-Simmons, M. Wonham, D. Secord, J. Barkas, B. Bingham, B. Bookheim, J. Byers, J. Chapman, J. Cordell, B. Dumbauld, A. Fukuyama, L. Harris, A. Kohn, K. Li, T. Mumford Jr., V. Radashevsky, A. Sewell, and K. Welch. 2000. Washington State exotics expedition 2000: A rapid survey of exotic species in the shallow waters of Elliott Bay, Totten and Eld inlets, and Willapa Bay. Washington Department of Natural Resources Nearshore Habitat Program Publication, Olympia.

den Hartog, C., and J. Kuo. 2006. Taxonomy and biogeography of seagrasses. Pages 1-23. in A. W. D. Larkum, R. J. Orth, and C. M. Duarte, eds. Seagrasses: Biol- ogy, ecology and conservation. Springer, The Netherlands.

Dumbauld, B. R., and S. Wyllie-Echeverria. 2003. The influence of burrowing thalassinid shrimps on the distribution of intertidal seagrasses in Willapa Bay, Washington, USA. Aquat. Bot. 77:27-42.

Ewanchuk, P. J., and S. L. Williams. 1996. Survival and re-establishment of vegetative fragments of eelgrass (Zostera marina). Can. J. Bot. 74:1584-1590.

Fong, C. W., S. Y. Lee, and R. S. S. Wu. 2000. The effects of epiphytic algae and their grazers on the intertidal seagrass Zostera japonica. Aquat. Bot. 67:251-261.

Gaeckle, J., P. Dowty, H. Berry, S. WyllieEcheverria, and T. Mumford. 2008. Puget Sound submerged vegetation monitoring project, 2006-2007 monitoring report. Washington Department of Natural Resources Nearshore Habitat Program, Olympia.

Grosholz, E. D., G. M. Ruiz, C. A. Dean, K. A. Shirley, J. L. Maron, and P. G. Connors. 2000. The impacts of a nonindigenous marine predator in a California bay. Ecology 81:1206-1224.

Hacker, S. D., D. Heimer, C. E. Hellquist, T. G. Reeder, B. Reeves, T. J. Riordan, and M. N. Dethier. 2001. A marine plant (Spartina anglica) invades widely varying habitats: Potential mechanisms of invasion and control. Biol. Invasions 3:211-217.

Hall, L. M., M. D. Hanisak, and R. W. Virnstein. 2006. Fragments of the seagrasses Halodule wrightii and Halophila jobnsonii as potential recruits in Indian River Lagoon, Florida. Mar. Ecol. Prog. Ser. 310:109117.

Harrison, P. G. 1982. Comparative growth of Zostera japonica Aschers. \& Graebn. and Z. marina L. under simulated intertidal and subtidal conditions. Aquat. Bot. 14:373379.

Harrison, P. G., and R. E. Bigley. 1982. The recent introduction of the seagrass Zostera japonica Aschers. and Graebn. to the Pacific coast of North America. Can. J. Fish. Aquat. Sci. 39:1642-1648.

Huong, T. T. L., J. E. Vermaat, J. Terrados, N. V. Tien, C. M. Duarte, J. Borum, and 
N. H. Tri. 2003. Seasonality and depth zonation of intertidal Halophila ovalis and Zostera japonica in Ha Long Bay (northern Vietnam). Aquat. Bot. 75:147-157.

Larned, S. T. 2003. Effects of the invasive, non-indigenous seagrass Zostera japonica on nutrient fluxes between the water column and benthos in a NE Pacific estuary. Mar. Ecol. Prog. Ser. 254:69-80.

Levin, P. S., J. A. Coyer, R. Petrik, and T. P. Good. 2002. Community-wide effects of nonindigenous species on temperate rocky reefs. Ecology 83:3182-3193.

Mack, M., D. Simberloff, W. Lonsdale, H. Evans, M. Clout, and F. Bazzaz. 2000. Biotic invasions: Causes, epidemiology, global consequences, and control. Ecol. Appl. 10:689-710.

Nomme, K. M., and P. G. Harrison. 1991a. A multivariate comparison of the seagrasses Zostera marina and Zostera japonica in monospecific versus mixed populations. Can. J. Bot. 69:1984-1990.

1991b. Evidence for interaction between the seagrasses Zostera marina and Zostera japonica on the Pacific coast of Canada. Can. J. Bot. 69:2004-2010.

Phillips, R. C. 1976. Preliminary observations on transplanting and a phenological index of seagrasses. Aquat. Bot. 2:93-101.

- 1984. The ecology of eelgrass meadows in the Pacific Northwest: A community profile. U.S. Fish Wildl. Serv. FWSOBS 84-24.

Phillips, R. C., and E. G. Menez. 1988. Seagrasses. Smithsonian Institution Press, Washington, D.C.

Pimentel, D., R. Zuniga, and D. Morrison.
2005. Update on the environmental and economic costs associated with alieninvasive species in the United States. Ecol. Econ. 52:273-288.

Shafer, D. J. 2007. Physiological factors affecting the distribution of the nonindigenous seagrass Zostera japonica along the Pacific coast of North America. Ph.D. diss., University of South Alabama, Mobile.

Shafer, D. J., T. D. Sherman, and S. WyllieEcheverria. 2007. Do desiccation tolerances control the vertical distribution of intertidal seagrasses? Aquat. Bot. 87:161-166.

Sokal, R. R., and F. J. Rohlf. 1995. Biometry. 3rd ed. W. H. Freeman and Co., New York.

Thom, R. M., B. Miller, and M. Kennedy. 1995. Temporal patterns of grazers and vegetation in a temperate seagrass system. Aquat. Bot. 50:201-205.

Thom, R. M., S. L. Southard, A. B. Borde, and P. Stoltz. 2008. Light requirements for growth and survival of eelgrass (Zostera marina L.) in Pacific Northwest (USA) estuaries. Estuaries Coasts 31:969-980.

Vermaat, J. E., and F. C. A. Verhagen. 1996. Seasonal variation in the intertidal seagrass Zostera noltii Hornem.: Coupling demographic and physiological patterns. Aquat. Bot. 52:259-281.

Wyllie-Echeverria, S., V. R. WyllieEcheverria, A. C. Churchill, and P. A. Cox. 2006. Further evidence for seed size variation in the genus Zostera: Exploratory studies with $Z$. japonica and $Z$. asiatica. Aliso 22:243-247. 